\title{
GT de Cibercultura da Compós: análise de temas e coautorias
}

\section{Raquel Recuero}

Doutora; Universidade Católica de Pelotas

raquelrecuero@gmail.com

\begin{abstract}
Resumo
O presente estudo explora os trabalhos apresentados no GT de Cibercultura da Compós a partir dos temas e coautorias presentes nestes trabalhos. O objetivo foi compreender as temáticas mais frequentes, bem como as coautorias do GT durante os anos. Buscamos, através de uma proposta metodológica que mistura análise de conteúdo e análise de redes, verificar e mensurar a presença de temas e de coautoria no grupo, e oferecer insights à produção do grupo e ao seu papel de gerar coautorias e colaborações entre os pesquisadores. Como conclusões principais, podemos apontar duas grandes temáticas emergentes (cultura digital e redes sociais na internet) e a presença baixa, mas crescente de coautorias no grupo.
\end{abstract}

\section{Palavras-chave}

Análise temática. Análise de redes. Cibercultura.

\section{Introdução}

O presente artigo constrói uma abordagem metodológica para analisar os artigos apresentados no grupo de trabalho (GT) de Cibercultura (ASSOCIAÇÃO..., 2013a) da Associação Nacional dos Programas de Pós Graduação em Comunicação (COMPOS) dos últimos dez anos. 0 GT, proposto pela primeira vez com essa denominação em 2006 (PRIMO, [2011]), foi, à época, o grupo mais votado na reclivagem da associação. 0 GT de Cibercultura foi proposto em substituição ao GT de Tecnologias Informacionais de Comunicação e Sociedade, que existia desde 2002. 0 grupo é um marco importante na pesquisa da área no Brasil, atuando como um forte demarcador de linhas de pesquisa que apoiavam a proposta de cibercultura dentro dos programas de pós-graduação no Brasil. Assim, pareceu-nos relevante 
examinar os rumos da pesquisa no grupo e as principais áreas que os pesquisadores ali exploram, bem como parcerias de pesquisa que ali se formaram.

Sendo assim, partimos de dois elementos de análise fundamentais. Queremos analisar as temáticas mais presentes nos trabalhos apresentados no grupo e, conjuntamente, as coautorias presentes no grupo. Questionamos quais as relações entre essas temáticas e as coautorias existentes e como o grupo pode ter ajudado a fomentar parcerias de pesquisa entre seus membros. Para tanto, apresentaremos uma proposta metodológica mista, que utiliza análise de redes e análise de contingência como elementos balizadores para a compreensão dos dados retirados da biblioteca da Compós. Nossa análise parte dos resumos e informações dos autores de trabalho do grupo.

\section{Referencial Teórico}

O estudo das colaborações, cooperações e temáticas de pesquisa tem sido bastante referenciado como modo de compreender a estrutura de grupos de pesquisa e cooperações no Brasil nas mais diversas áreas (ZAGO; BASTOS; RECUERO, 2015; BRZEZINSKI; GARRIDO, 2001; TREIN; CIAVATTA, 2003). Particularmente, o estudo dessas colaborações e perspectivas temáticas é relevante para se identificar elementos tais como temáticas emergentes, núcleos de colaboração e a estrutura geral da pesquisa das várias áreas. Com relação aos grupos de trabalho da Compós, outros trabalhos já focaram a análise das citações, descrevendo os autores mais citados, tipo de publicação mais presente etc. (PRIMO et al., 2008). Nesse tipo de estudo, de caráter mais bibliométrico, os autores buscaram identificar elementos estruturais e temáticos da pesquisa e das citações dos grupos de trabalho. Entretanto, nenhum desses trabalhos focou questões temáticas e coautorias de modo particular ao grupo de trabalho de Cibercultura.

Deste modo, estudos de colaborações baseados na análise dos currículos Lattes têm identificado estruturas diferentes nas diversas subáreas (MENA-CHALCO; DIGIAMPIETRI; CESAR JUNIOR, 2012; BASTOS, 2015). Essas estruturas traduzem elementos relevantes, como colaborações mais notadamente inter ou intrainstitucionais (ZAGO; BASTOS; RECUERO, 2015). Muitos desses estudos são resultado de trabalhos de análise de redes sociais, que tem se revelado um método eficiente para o estudo dessas estruturas de redes. A análise de redes sociais, assim, é importante por mostrar a estrutura das redes e classificar e modular esses grupos, bem como medir a estrutura dessas redes, de modo bastante semelhante ao 
que faremos neste trabalho. Para estas análises, métricas de centralidade (como grau, intermediação, proximidade e etc.) já foram utilizadas.

A Análise de Redes Sociais utiliza uma série de métricas que podem auxiliar a observar as redes de coautorias e colaborações e as estruturas de rede, em geral (DEGENNE; FORSÉ, 1999; WASSERMAN; FAUST, 1994). A abordagem trabalha com as redes como sendo constituídas dos nós e suas conexões, e utiliza métricas topológicas para a análise da estrutura dessas redes (representadas por grafos). Algumas métricas são denominadas globais, quando focam a rede como um todo, e outras, individuais, ou seja, que focam características individuais dos atores da rede (ou métricas de rede inteira e métricas individuais) (MENACHALCO; DIGIAMPIETRI; CESAR JUNIOR, 2012). A escolha dessas métricas é a mais variada na bibliografia e depende do tamanho da rede a ser analisada também. No caso das redes do GT de Cibercultura, trabalhamos com um conjunto de dados relativamente pequeno (100 trabalhos e um grupo de 42 autores), por isso optamos por algumas métricas específicas. Rapidamente focaremos duas métricas bastante utilizadas nas análises bibliométricas de coautoria e nas análises de rede em geral: Grau e Modularidade.

O grau é delimitado na Análise de Redes Sociais como métrica de centralidade do nó. Quanto maior o grau, maior o número de conexões que cada nó recebe. A medida de grau é uma medida de centralidade. Quanto maior o grau, mais "importante" é aquele nó dentro de uma determinada rede. 0 número de arestas de cada nó (que determina seu grau) é um indicativo importante da importância deste nó. Em termos de colaborações e coautorias, o grau representa o número de conexões com outros autores (coautorias).

Já a modularidade é uma médida de grupabilidade. Preocupa-se em delimitar a probabilidade de um determinado nó pertencer a um grupo ou outro, dentro da mesma rede, auxiliando a identificar clusters. Essa métrica já foi usada para delimitar grupos de coautores (ZAGO, BASTOS; RECUERO, 2015).

Em nosso trabalho, entretanto, interessam-nos também as temáticas mais frequentes do GT de Cibercultura, queremos identificar as temáticas mais comuns. Para tanto, utilizaremos análise de conteúdo, que se preocupa com a análise de elementos dos dados textuais como a frequência e a classificação desses dados em grandes categorias (BARDIN, 2011; CARRIGNTON; SCOTT; WASSERMAN, 2005), e também fundamentos de um braço desta análise de conteúdo, denominado análise de contingência (OSGOOD, 1959). A análise de contingência dá atenção às associações entre os conceitos mais do que a sua mera frequência num conjunto de dados. Essas premissas conjuntas auxiliarão a construir um modo de análise 
que poderá ser, então, observado a partir da análise de redes, na qual não observaremos simplesmente as relações, mas sua importância para o todo.

A análise de conteúdo prevê a análise da frequência de palavras no conjunto de um corpus, ou seja, o número de vezes que essas palavras aparecem entre determinadas unidades. Essas palavras são, então, classificadas em conceitos mais amplos, e esses conceitos mais amplos analisados em termos de coocorrências entre si. Assim, esses conceitos são observados também como rede, ou seja, como estrutura interconectada.

Os temas e suas interconexões são elementos importantes para que possamos compreender as temáticas de modo mais complexo. Para isso, também utilizaremos as métricas de análise de redes, para compreender a estrutura da rede temática (conceitual) dentro do GT. Embora esse tipo de estudo já tenha sido apresentado em outros trabalhos (RECUERO; BASTOS; ZAGO, 2015), pouco dele foi utilizado para que se compreendam elementos bibliométricos de temáticas e emergência de temáticas em grupos de trabalho.

\section{Metodologia}

Para analisar os artigos apresentados no GT de Cibercultura da Compós, consultamos a biblioteca da associação, disponível online, e baixamos todos os PDFs dos 100 textos publicados no Grupo de Trabalho de Cibercultura entre 2006 e 2015, ou seja, nos dez últimos anos, com 42 autores. Todos os dados utilizados neste trabalho estão publicamente disponíveis no site da Compós, na parte da Biblioteca da associação (ASSOCIAÇÃO..., 2013b).

De posse deste material, separamos os dados em dois subconjuntos, a partir dos quais serão analisadas as temáticas e informações de coautorias dos trabalhos. Os títulos e resumos dos textos se constituíram no primeiro subconjunto, onde foram analisadas as temáticas e conceitos mais importantes, considerando que ali encontraríamos a parte mais central dos artigos. Para tanto, consideramos cada resumo e título como unidades individuais, cujas ocorrências de palavras foram analisadas em relação aos demais no grupo de trabalho. Analisamos palavras com uma frequência mínima de dez vezes no conjunto de dados. A partir daí, observamos as temáticas mais comuns. Essas temáticas foram analisadas em relação umas com as outras, de modo a delimitar suas relações entre si, e a elas foram aplicadas métricas de análise de redes, conforme o capítulo anterior.

No segundo subconjunto, analisamos informações de autoria e coautoria dos artigos. Esses dados também foram analisados em termos de estrutura de rede, sendo também 
submetidos a métricas de análise de redes, de modo a compreender-se como essas estruturas descrevem práticas de colaboração no GT.

Para fins de facilitar a análise temporal, os dados também foram divididos entre os últimos cinco anos e os cinco anos anteriores (totalizando dez anos) de forma arbitrária. 0 objetivo foi aquele de proporcionar espaço comparativo desses dados, de modo a desvelar particularidades relativas à própria evolução do grupo de trabalho como um todo.

Os grafos apresentados nesta análise foram gerados com o Gephi (c2015) e o NodeXL (c2015), ferramentas também utilizadas para o cálculo das métricas explicitadas na primeira parte do trabalho.

\section{Análise}

A partir dos dados coletados, analisamos primeiramente as temáticas recorrentes e, logo após, as coautorias no GT. Finalmente, cruzamos os dados de temáticas e coautorias para um quadro mais completo dos dados.

\subsection{Temáticas mais recorrentes}

No primeiro recorte, analisamos, a partir de conceitos-chave, os títulos e os resumos dos trabalhos apresentados. Nosso objetivo é verificar como as temáticas foram alteradas nos últimos anos no GT. Para tanto, analisaremos dois grupos de cinco anos, de 2006 a 2010 e de 2011 a 2015.

\subsubsection{Temáticas de 2006-2010}

No primeiro mapa, temos as principais temáticas que apareceram no GT de 2006 a 2010. Entre os conceitos mais citados, temos "cibercultura" (27 ocorrências), "comunicação" (23 ocorrências), "sociais" (23 ocorrências), "redes" (19 ocorrências), "mídia" (17 ocorrências), "cultura" (15 ocorrências) e "tecnologias" (15 ocorrências).

Na Figura 1, vemos os conceitos referentes aos temas mais frequentes no GT, neste período, em maior tamanho, e as conexões indicam coocorrências entre esses temas. A associação entre diferentes conceitos (força da conexão) indica temáticas mais abrangentes, decorrentes da coocorrência desses elementos (OSGOOD, 1959). As cores apresentam grupos de temáticas que tendem a coocorrer, a partir do conceito de modularidade, na análise de redes (RECUERO; BASTOS; ZAGO, 2015). 
Figura 1 - Grafo representando as coocorrências temáticas no GT de Cibercultura de 2006-2010.

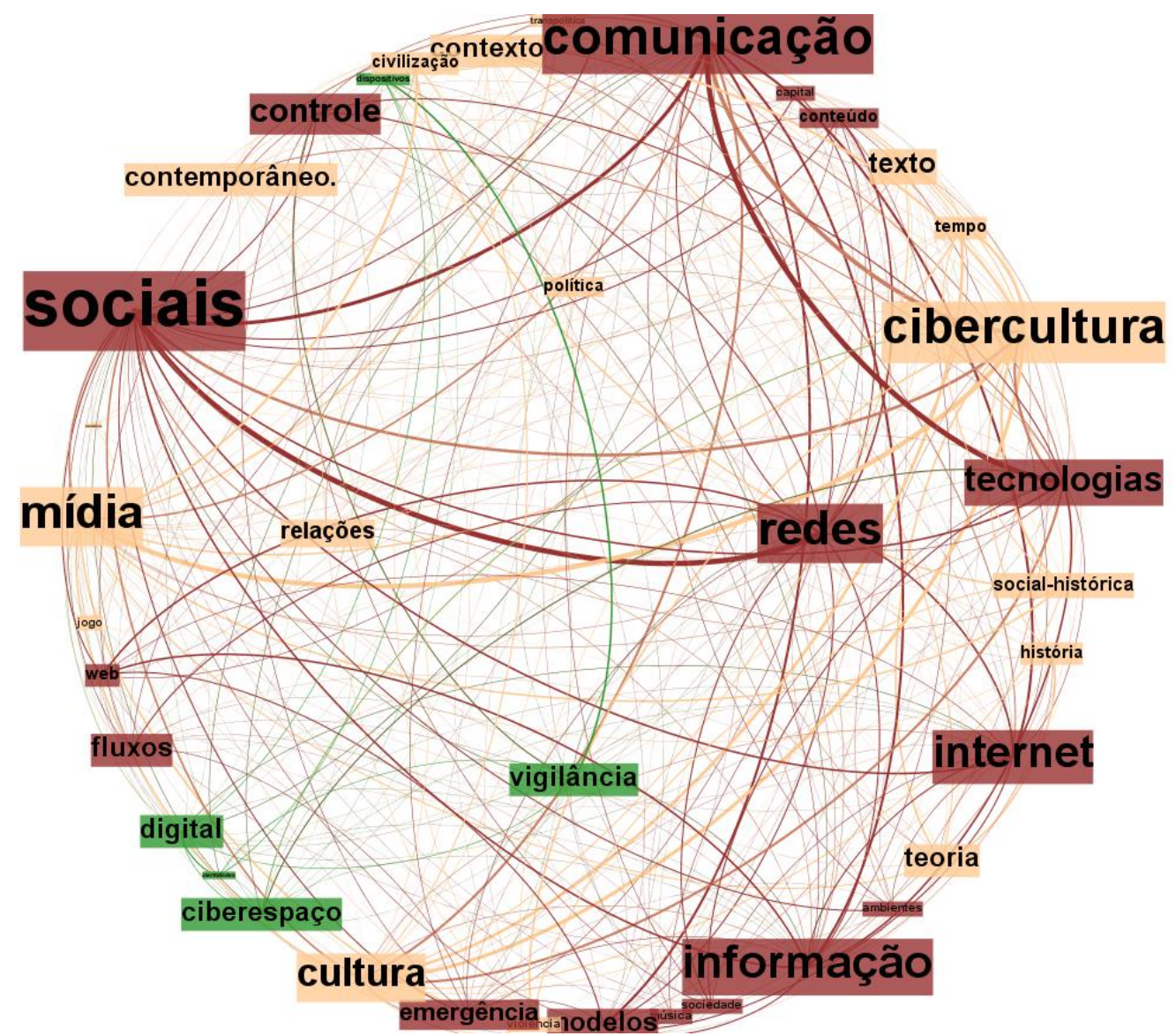

Fonte: da autora.

Nas temáticas centrais, assim, estão "cibercultura", "comunicação", "mídia" e "redes". "Comunicação" está bastante conectada com "tecnologias" e "sociais". "Redes", por sua vez, também está bastante conectada com "sociais" e "informação". "Mídia" e "cibercultura" também aparecem fortemente conectadas, juntamente com "cultura". A Tabela 1 delimita esses dados de modo mais claro.

Tabela 1 - Módulos, temáticas e conceitos associados.

\begin{tabular}{|c|c|l|}
\hline Cor & Temática & \multicolumn{1}{c|}{ Conceitos } \\
\hline Verde & "Vigilância" & Digital, vigilância, ciberespaço, dispositivos, cibercidades. \\
\hline Vermelho & $\begin{array}{l}\text { "Informação e } \\
\text { Redes Sociais" }\end{array}$ & $\begin{array}{l}\text { Redes sociais, comunicação, tecnologias, informação, in- } \\
\text { ternet, fluxos, modelos, controle, emergência, conteúdo, } \\
\text { web, capital, ambientes, sociedade e pública. }\end{array}$ \\
\hline Bege & "Cultura Digital" & $\begin{array}{l}\text { Cultura, cibercultura, mídia, contemporâneo, teoria, con- } \\
\text { texto, civilização, tempo, texto, relações, história, social- } \\
\text { histórica, política, teoria, jogo, transpolítica. }\end{array}$ \\
\hline
\end{tabular}

Fonte: da autora. 
Na Figura 2 vemos como esses conceitos estão interconectados a partir de seu grau e suas relações (DEGENNE; FORSÉ, 1999; WASSERMAN; FAUST, 1994), com foco específico na grupabilidade. Essa métrica nos auxilia a observar de modo separado conceitos que tendem a pertencer a um mesmo grupo, ampliando a perspectiva de tema de pesquisa.

Figura 2 - Grafo representando rede temática delimitada por grupos de conceitos no período de 2006-2010.

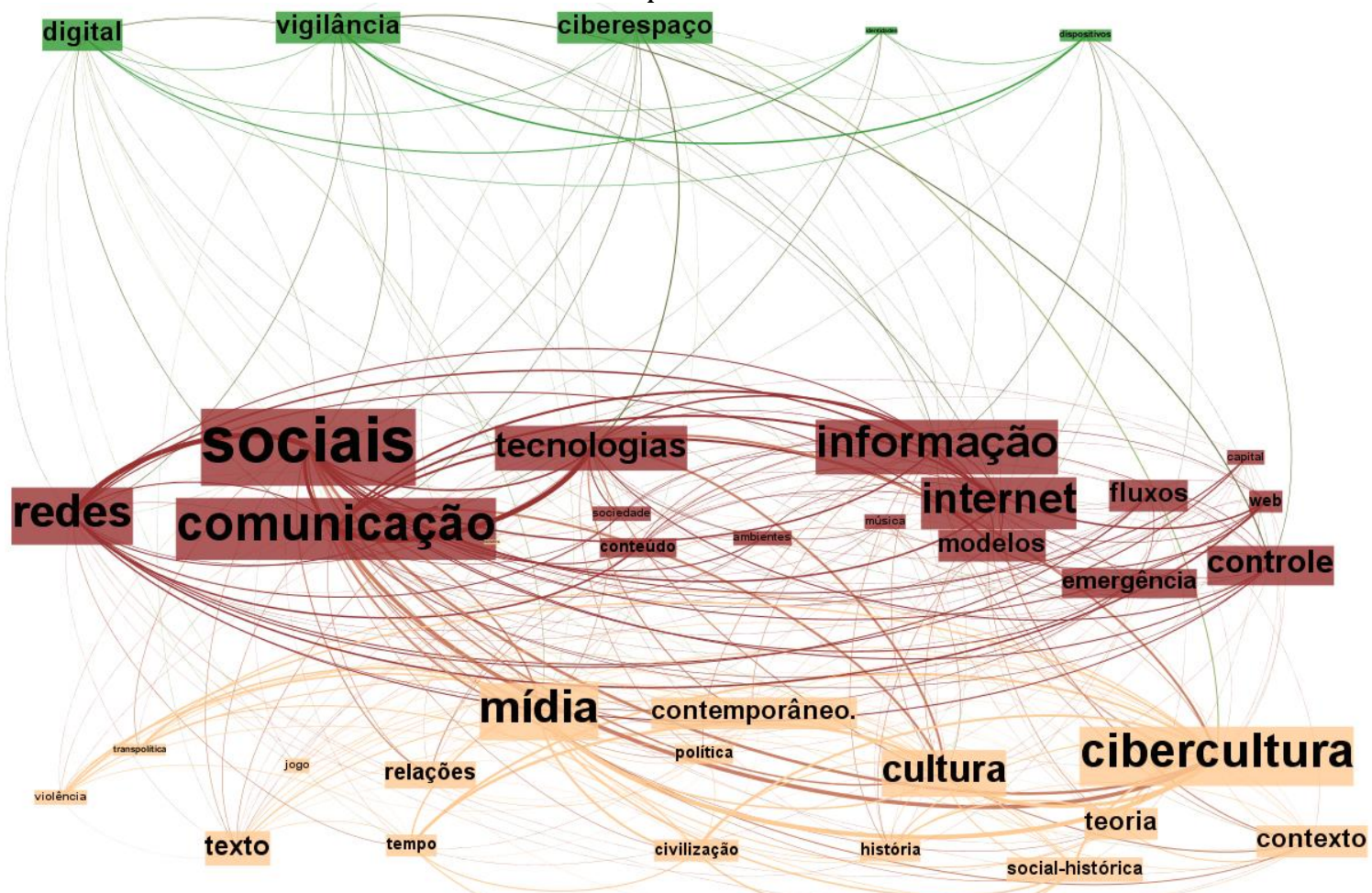

Fonte: da autora.

Podemos ver, assim, que há três grandes módulos que aparecem de modo interrelacionado. 0 primeiro, em verde, mostra uma grande conexão entre os conceitos de "vigilância", "ciberespaço", "digital", "identidades" e "dispositivos". Este grupo aparece mais fracamente conectado aos outros dois. Ao centro, em vermelho, temos o maior módulo, centrado em elementos como "redes sociais" (dois conceitos mais conectados no grupo), "tecnologias de comunicação", "informação" e "internet". Finalmente, o terceiro grupo, que também é fortemente interconectado, mostra como conceitos centrais "mídia", "cultura" e "cibercultura".

Essas análises mostram que as temáticas desses anos estão bastante construídas em torno de "redes sociais", mas com uma abordagem mais informacional, no sentido de se perceberem questões de fluxo de informação e elementos de sociabilidade. A questão da "cultu- 
ra digital" é outra temática forte, com impacto mais amplo, especialmente em questões de contexto e mídia. Finalmente, a terceira temática foca a questão da vigilância. Além disso, podemos dizer que, transversalmente, as questões políticas da comunicação mediada pelo computador também aparecem (notadamente na questão da vigilância e fortemente no grupo da cultura digital).

\subsubsection{Temáticas de 2011-2015}

Utilizando a mesma abordagem para a análise das temáticas dos cinco anos seguintes, temos diferentes resultados. Observamos que o conceito mais citado é "redes" (47 ocorrências), seguido de "sociais" (43). A seguir, "comunicação" (32 ocorrências), "digital" (26), "teoria” (25), "ator-rede” (14), "cibercultura” (14), "games" (14), “Twitter” (14) (Figura 3).

Na Figura 3, vemos os temas mais frequentes em tamanho maior, e suas conexões mostram a frequência da coocorrência. No caso, vemos que o GT parece ter centrado a produção sobre três eixos principais: "rede social" (com o conceito de "rede" ao centro), "teoria ator-rede" e "comunicação digital". A centralidade dos conceitos "teoria", "mídia", "redes", "sociais", "tecnologias", "relações", "ator-rede", "comunicação" e "música" mostra um centro de conceitos que estão relacionados às temáticas que ficam no entorno no grafo. As associações entre essas temáticas, novamente, desvelam elementos importantes entre os diferentes conceitos usados e suas associações (OSGOOD, 1959). 
Figura 3 - Grafo representando rede temática de conceitos do GT de 2011-2015.

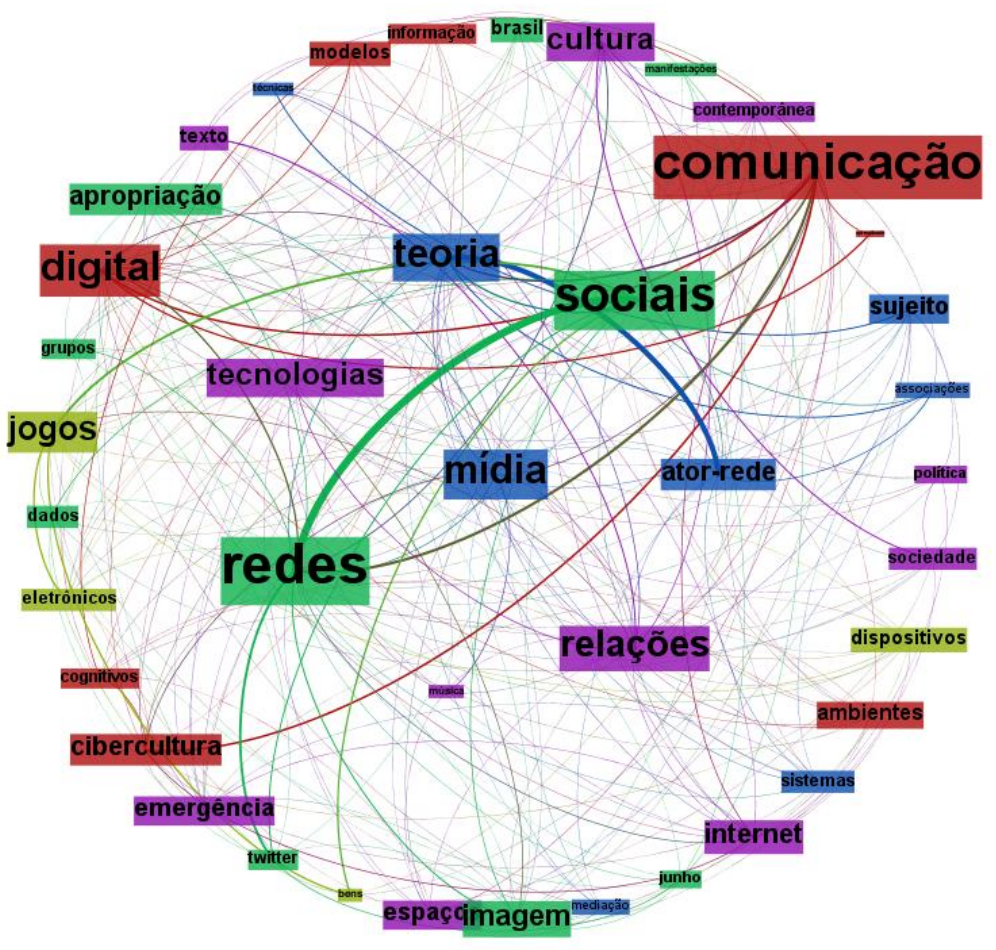

Fonte: da autora.

Com as cores, podemos ver os grupos dos diferentes conceitos, conforme a Tabela 2 a seguir. Esses grupos demarcam, novamente, temáticas específicas desveladas pela métrica de grupabilidade (MENA-CHALCO; DIGIAMPIETRI; CESAR JUNIOR, 2012; RECUERO; BASTOS; ZAGO, 2015).

Tabela 2 - Módulos, temáticas e conceitos associados.

\begin{tabular}{|c|c|l|}
\hline Cor & Temática & \multicolumn{1}{c|}{ Conceitos } \\
\hline Vermelho & "Cognição" & $\begin{array}{l}\text { Digital, comunicação, cibercultura, informação, } \\
\text { modelos, ambientes, cognitivos. }\end{array}$ \\
\hline Azul & "Teoria Ator-Rede" & $\begin{array}{l}\text { Teoria, mídia, ator-rede, associações, sujeito, téc- } \\
\text { nicas, mediação, sistemas. }\end{array}$ \\
\hline Rosa & "Cultura Digital" & $\begin{array}{l}\text { Tecnologias, relações, política, sociedade, internet, } \\
\text { emergência, música, cultura, texto, contemporâ- } \\
\text { nea. }\end{array}$ \\
\hline Verde & "Redes Sociais" & $\begin{array}{l}\text { Redes, sociais, apropriação, grupos, dados, Brasil, } \\
\text { manifestações, junho, Twitter, imagem. }\end{array}$ \\
\hline Verde-claro & "Jogos Eletrônicos" & Jogos, eletrônicos, bens, dispositivos. \\
\hline
\end{tabular}

Fonte: da autora. 
A Figura 4 mostra a presença (grau) dos conceitos dentro de cada grupo e suas interrelações. Podemos observar na figura cinco temáticas centrais, por assim dizer. A primeira delas, representada pelo grupo verde, está diretamente relacionada ao estudo das redes sociais, que tem aparecido principalmente sob a forma de estudos aplicados com dados, via Twitter (relativos às manifestações no País em 2013 e 2014). A segunda, representada pelo grupo azul, foca a teoria ator-rede, de Latour, e suas aplicações para os estudos de mídia. 0 terceiro grupo, em rosa, parece voltar-se para as relações entre tecnologia e sociedade, notadamente no âmbito das relações culturais e de produtos culturais, ou, ainda, da cultura digital. 0 quarto grupo, em vermelho, aparece com a temática da cognição, fortemente associada aos estudos da cibercultura. E o último grupo, em verde claro, foca a questão dos jogos eletrônicos.

Figura 4 - Grafo representando rede temática delimitando grupos de conceitos.

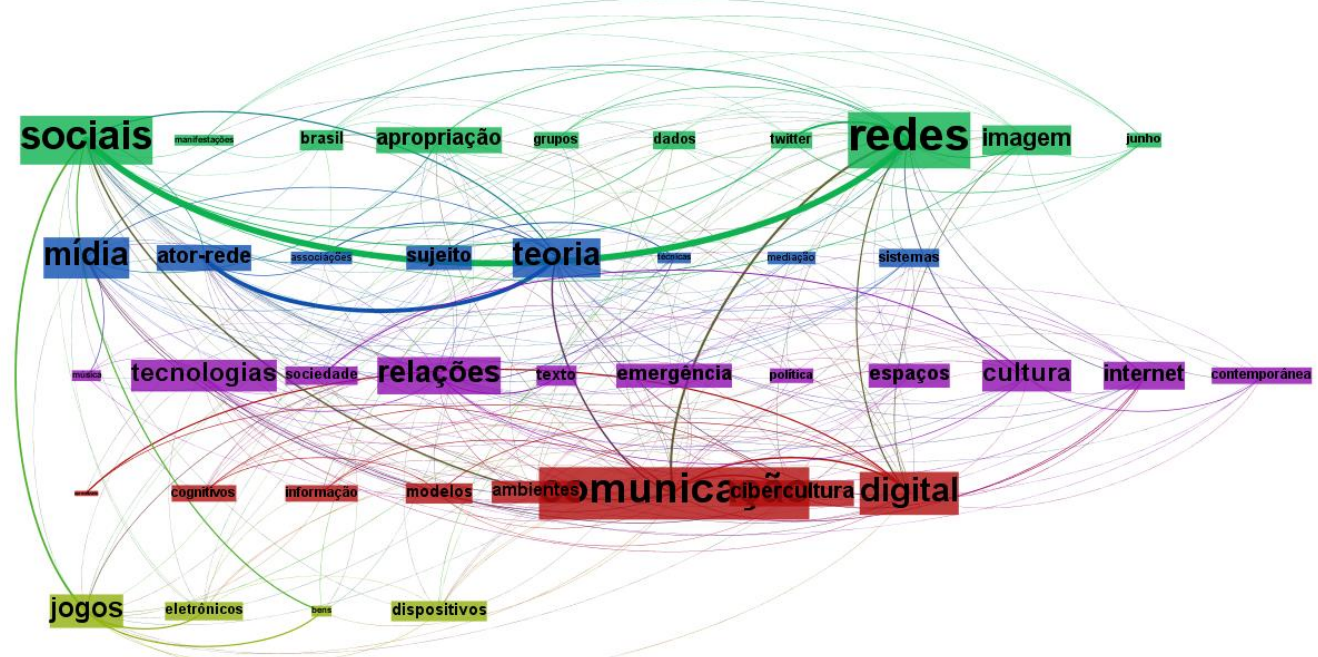

Fonte: da autora.

Podemos dizer que as temáticas nestes anos alteraram-se com mais força. Não só temos mais grupos temáticos, o que indica uma maior pluralização dos temas, mas igualmente menos conceitos fortes. A temática das "redes sociais" continua aparecendo de modo forte, mas focada em pesquisa aplicada, com objetos (como o Twitter e os protestos) aparecendo com mais força. A temática da "cultura digital" torna-se mais focada em objetos específicos 
(música, espaços etc.). Além disso, surgem três outros focos: a temática dos jogos, a temática da cognição e a temática da "teoria ator-rede".

Comparativamente, vemos que há um ganho de espaço para as aplicações das pesquisas, com conceitos mais focados em objetos e temáticas bem mais específicas do que nos cinco anos anteriores. Vemos, também, a redução de importância de conceitos que antes eram chaves, como "cibercultura", "tecnologias" e "informação". Por outro lado, o conceito de "redes" cresce bastante, e aumenta sua conexão com "sociais", indicando um ganho de espaço deste foco.

\subsection{Coautorias no GT Cibercultura}

Embora o número de trabalhos em coautoria tenha aumentado no GT nos últimos cinco anos (16 trabalhos contra apenas oito nos cinco anos anteriores), é somente a partir de 2010 que esses trabalhos aparecem com mais força. Entre 2005 e 2009, por exemplo, há apenas cinco trabalhos em coautoria (Tabela 3 ).

Tabela 3 - Número de coautorias de artigos por ano.

\begin{tabular}{|c|c|c|c|c|c|c|c|c|c|c|}
\hline Ano & $\mathbf{2 0 1 5}$ & $\mathbf{2 0 1 4}$ & $\mathbf{2 0 1 3}$ & $\mathbf{2 0 1 2}$ & $\mathbf{2 0 1 1}$ & $\mathbf{2 0 1 0}$ & $\mathbf{2 0 0 9}$ & $\mathbf{2 0 0 8}$ & $\mathbf{2 0 0 7}$ & $\mathbf{2 0 0 6}$ \\
\hline $\begin{array}{c}\text { Total coau- } \\
\text { torias }\end{array}$ & 2 & 3 & 4 & 4 & 3 & 3 & 2 & 1 & 1 & 1 \\
\hline$\%$ total & $20 \%$ & $30 \%$ & $40 \%$ & $40 \%$ & $30 \%$ & $30 \%$ & $20 \%$ & $10 \%$ & $10 \%$ & $10 \%$ \\
\hline
\end{tabular}

Fonte: da autora.

Observamos, portanto, que a partir de 2010, há um aumento de coautorias. No total, o GT de Cibercultura tem 24 trabalhos com mais de um autor, 24\% do total de 100 trabalhos apresentados no período, com uma clara tendência a um aumento desses números nos últimos cinco anos. A maioria das coautorias é notadamente intrainstitucional. Nos primeiros cinco anos, temos três trabalhos em coautorias interinstitucionais, de um total de oito. Cinco coautorias, portanto, são intrainstitucionais. Nos cinco anos seguintes, temos mais cinco coautorias interinstitucionais de um total de 16 coautorias, sendo nove, portanto, intrainstitucionais. No mapa a seguir (Figura 5) vemos as coautorias totais dos dez anos de GT. 
Figura 5 - Rede de coautorias de artigos do GT Cibercultura de 2006-2015. As conexões representam o número de coautorias entre cada grupo de pesquisadores.

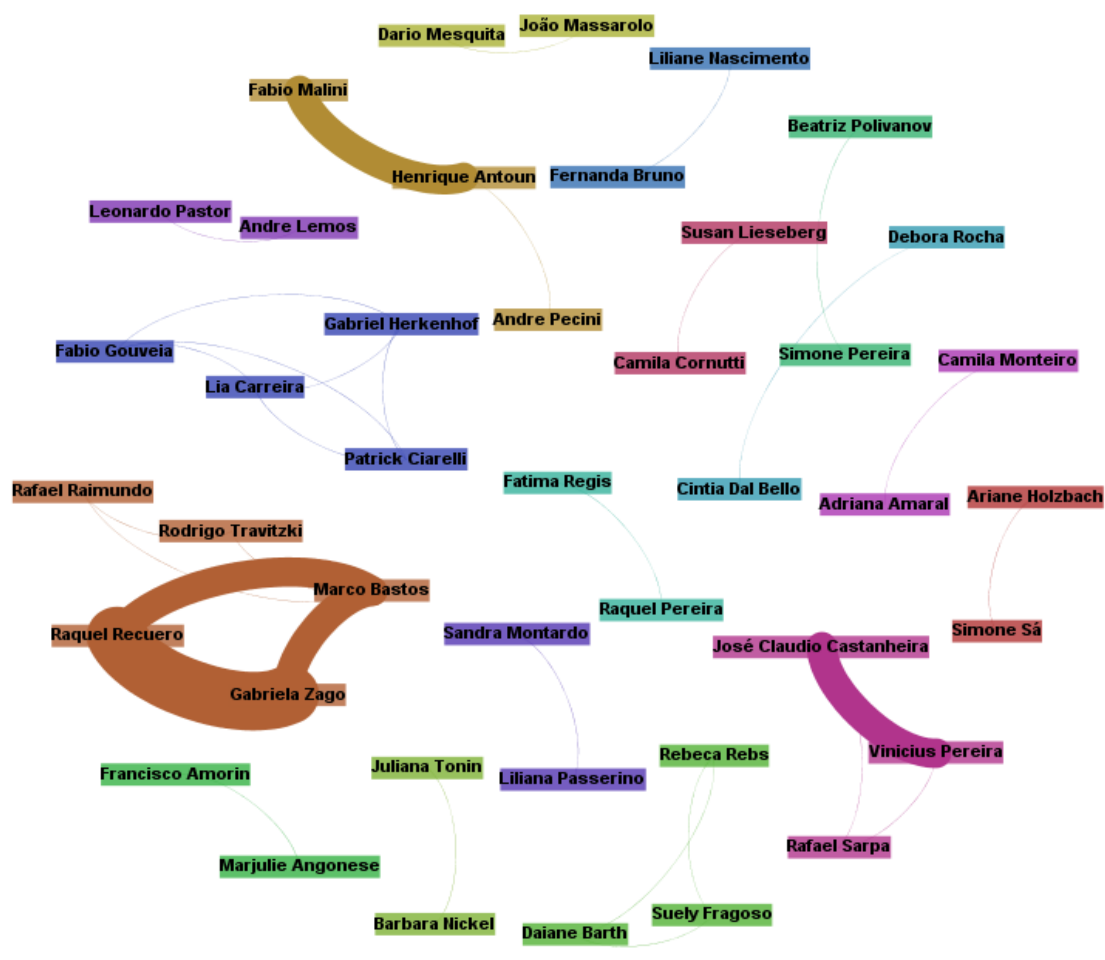

Fonte: da autora.

Para analisar as coautorias, utilizamos métricas específicas de análise de redes, demarcando os clusters (grupos) com maior número de colaborações (arestas mais grossas), além do tamanho dos nós indicar o grau, ou seja, número de coautorias por autor (nos termos de MENA-CHALCO; DIGIAMPIETRI; CESAR JUNIOR, 2012; ZAGO; BASTOS; RECUERO, 2015). Os grupos de coautores foram delimitados por cores que representam modularidade (a tendência a grupabilidade, ou seja, a um determinado nó, na rede, pertencer ao mesmo grupo A ou B ).

Há clusters que se formam com o passar do tempo, com a participação de pesquisadores que passam a construir trabalhos conjuntos, o que demonstra que o GT também atua como elemento de inserção para algumas coautorias, notadamente nos clusters com conexões mais fortes, que indicam várias coautorias entre os pesquisadores em questão. Outros clusters mostram coautorias mais esporádicas, que ocorreram apenas uma vez.

Vemos, assim, que a maioria das coautorias é focada em colaborações entre pesquisadores da mesma instituição. As colaborações entre pesquisadores de diferentes instituições, 
apesar de sempre em menor número, aumentaram significativamente nos últimos anos. A seguir, examinaremos essas colaborações por período de tempo.

\subsubsection{Coautorias e colaborações no período 2006-2010}

Na Figura 6 vemos as coautorias do período. São sete clusters, sendo três com mais de dois autores. A representação está demarcada por clusters (grupos de coautores) indicados por cor. 0 tamanho dos nós representa o número de coautorias, e a força da conexão (espessura) o número de coautorias entre cada dupla de autores. A rede é bastante desconectada, pois não há pontes entre os grupos. Apesar disso, vários autores coautoram artigos com outros autores do GT, mostrando a formação de parcerias de pesquisa.

Figura 6 - Rede de coautorias de artigos apresentados no GT de 2006 a 2010.
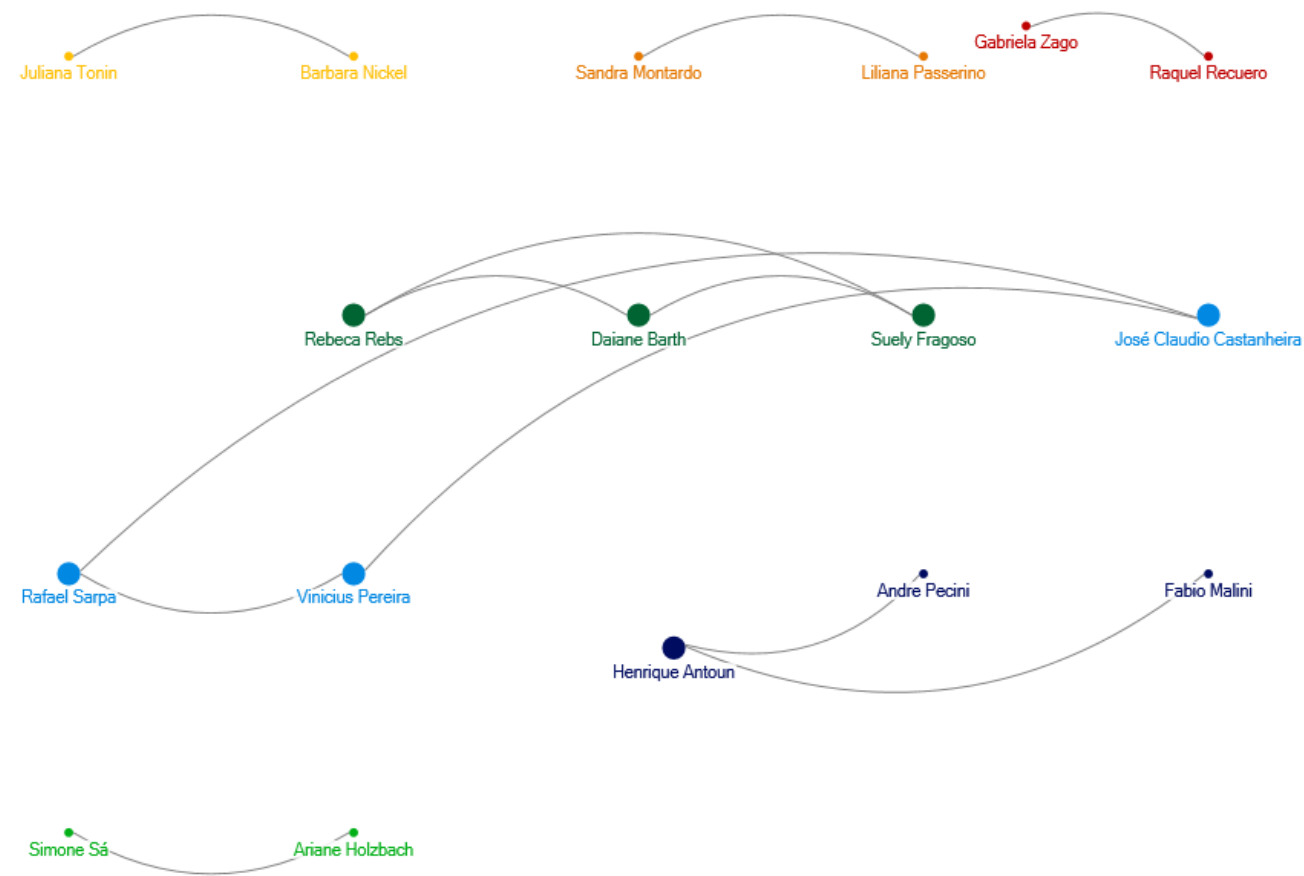

Created with NodeXL (http:I/nodexl.codeplex.com)

Fonte: da autora.

\subsubsection{Coautorias e colaborações de 2011 a 2015}

Na Figura 7 vemos os autores com sua representação demarcada por grau (número de coautorias com outros autores), quanto maior a esfera, maior o número de coautorias. As conexões entre os autores demonstram o número de coautorias entre eles, quanto mais 
grossa a conexão, maior o número de coautorias. As cores mostram modularidade, ou seja, autores que tendem a publicar entre si. Como a rede é bastante desconectada (há poucas coautorias entre os grupos), praticamente cada conjunto de coautores é um grupo. Dentre as instituições dos participantes, os dois módulos com maior número de coautorias representam pesquisadores de universidades diferentes, mas todos os demais representam pesquisadores da mesma instituição, ao menos, à época da coautoria.

Figura 7 - Rede de coautorias de artigos apresentados no GT de 2011 a 2015.
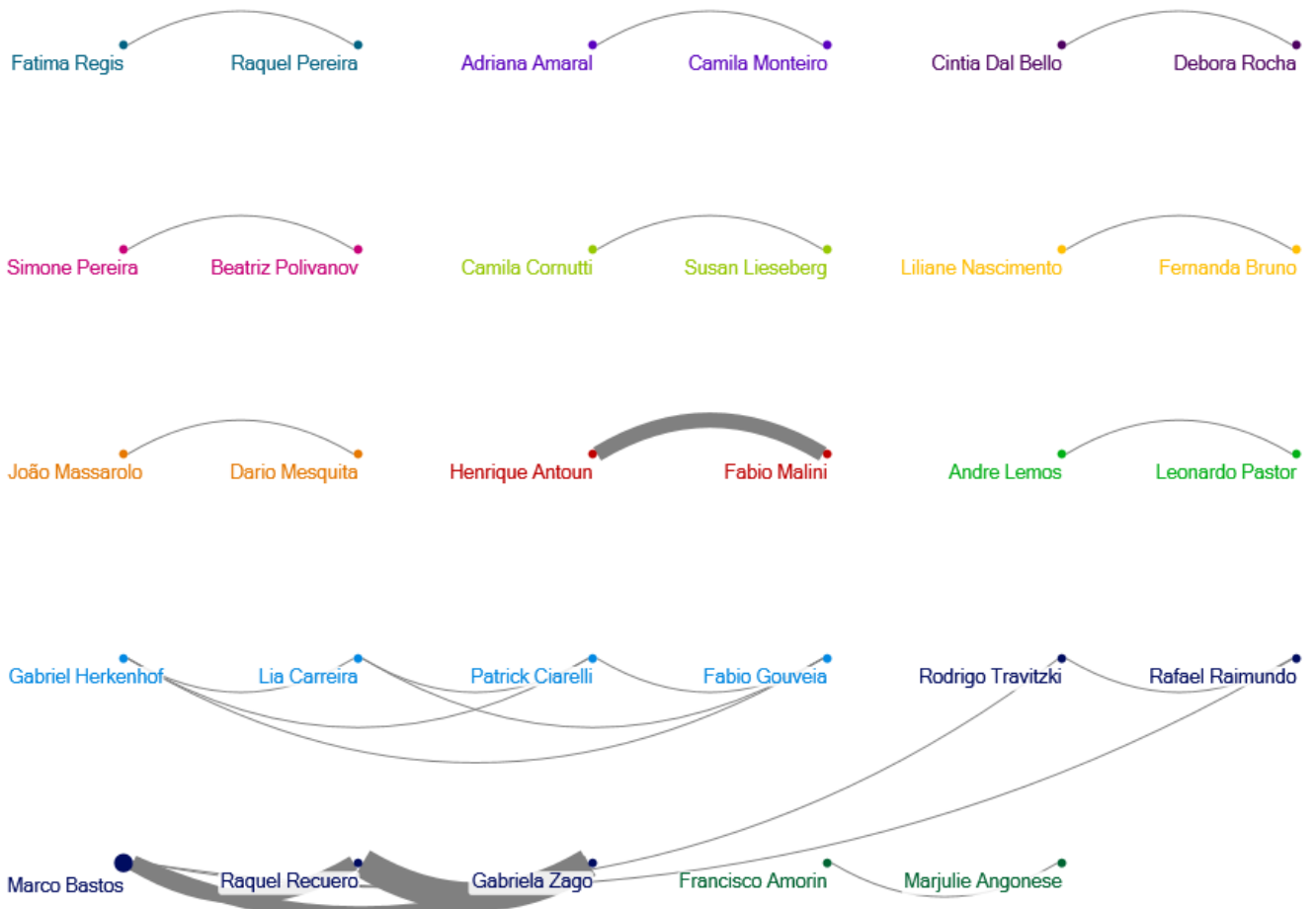

Fonte: da autora.

\subsection{Coautorias e Temáticas}

Finalmente, nesta sessão vamos discutir as relações entre temáticas e coautorias, e explorar de que modo esses elementos estão relacionados. Vimos, nos capítulos anteriores, as temáticas mais exploradas pelo GT e suas conexões.

Na Tabela 4, vemos o cruzamento das temáticas mais frequentes cujos objetos foram explorados através de artigos em coautoria com os grupos de coautores. Como há mais de uma temática onde um determinado número de coautores participou, o número é um pouco maior do que o total de coautorias. 
Tabela 4 - Coautorias de artigos apresentados no GT e suas temáticas.

\begin{tabular}{|c|c|c|c|}
\hline Temática & Total de Artigos & Coautorias & Autores \\
\hline "Redes sociais" & 11 & 08 & 19 \\
\hline "Cultura digital" & 16 & 14 & 28 \\
\hline "Cognição" & 1 & 1 & 2 \\
\hline "Vigilância" & 2 & 2 & 2 \\
\hline
\end{tabular}

Fonte: da autora.

A temática com maior número de coautorias é a de "cultura digital", cujo foco está nos objetos culturais apreendidos e construídos na Cibercultura. Neste grupo, há o maior número de coautorias intrainstitucionais, principalmente em trabalhos com dois coautores. 0 número total de artigos indica que houve mais de uma apresentação de trabalho pelo mesmo grupo de coautores no período analisado.

A segunda temática com maior número de coautorias é "redes sociais", com um total de 11 artigos e oito coautorias. É a temática também onde a média de autores por trabalho é maior, com 2,4, indicando que a maioria dos trabalhos aqui foi escrito por grupos de mais de dois autores em parceria.

A terceira temática é a da "vigilância", com dois trabalhos e dois coautores. Finalmente, a última temática com coautorias é a de "cognição", com apenas um trabalho.

Esses dados indicam o crescimento da pesquisa aplicada, em coautoria, especialmente com foco nas temáticas de "cultura digital" e "redes sociais". Nesses dois centros, concentram-se pesquisas de caráter mais aplicado, focadas em objetos e dados, sua presença tendo crescido no GT, indicando uma mudança no período analisado.

Esses dados também mostram que, embora o número total de coautorias tenha crescido, bom como a colaboração entre diferentes grupos e diferentes universidades nos últimos cinco anos, ainda é incipiente a colaboração mais ampla entre os membros do GT. Também mostram que, dentre as variadas temáticas observadas no GT, foram as temáticas de "Redes Sociais" e "Cultura Digital" aquelas que mais obtiveram grupos de coautores atuando juntos.

Outro detalhe observado é que as coautorias também aparecem, principalmente, focadas em colaborações esporádicas e não trabalhos de longo prazo, com raras exceções. Dentre os coautores nos dados analisados, vemos vários grupos independentes, ou seja, sem coautoria entre si. Observa-se também que há um crescimento do número de grupos de coautores e que, em alguns casos, o número de coautorias entre os mesmos autores foi frequente no GT. 


\section{Conclusão}

Neste trabalho, buscamos utilizar uma combinação de métodos para compreender temáticas de pesquisa emergentes nos dez anos de existência do GT de Cibercultura da Compós. Para este estudo, buscamos elementos da Análise de Conteúdo (BARDIN, 2011; CARRIGNTON; SCOTT; WASSERMAN, 2005), focada em classificação de conceitos com base na frequência de palavras nos resumos dos trabalhos apresentados no GT e nas coocorrências (elementos de associação entre os conceitos, a partir da análise de contingência de OSGOOD, 1959). A partir dessa abordagem, delimitamos quais conceitos foram mais presentes nos resumos do grupo de trabalho e, pelas suas associações, através da analise de redes, buscamos compreender grupos temáticos presentes nesses resumos. Através destes passos, pudemos identificar três grandes grupos temáticos no período de 2006-2010, e cinco grupos temáticos no período de 2011-2015. Esse conjunto de dados permitiu-nos observar a presença de algumas temáticas comuns, como a das "Redes Sociais" e a da "Cultura Digital", que têm sido largamente exploradas no grupo. Além disso, pudemos também observar a presença maior de pesquisa aplicada nos últimos anos.

Quando observamos os dados de coautorias, pudemos verificar a presença de diversas coautorias no GT. Através da análise de redes, pudemos observar coautorias entre autores diferentes no decorrer do tempo, bem como a construção de grupos. Essas coautorias, entretanto, foram bastante restritas a grupos da mesma origem, da mesma universidade, de forma análoga à observada por Zago, Bastos e Recuero (2015). Apesar disso, pudemos observar coautorias interinstitucionais florescerem no GT, especialmente no que diz respeito aos últimos cinco anos. Também há grupos que se formam entre coautores diferentes, em torno de temáticas emergentes. Isso é interessante porque mostra que o GT também pode atuar como um espaço de colaboração entre os pesquisadores.

A temática com maior número de coautorias foi aquela em torno da "Cultura Digital". Entretanto, essas coautorias foram construídas principalmente de modo intrainstitucional. Já a temática de "Redes Sociais" foi aquela com maior número de coautorias interinstitucionais, mostrando um potencial importante, principalmente relacionado à pesquisa aplicada.

Este trabalho buscou, assim, analisar os últimos dez anos de produção do GT de Cibercultura da Compós. A partir de uma abordagem mista, buscamos explorar as temáticas mais presentes e suas relações com coautorias. Dentre as limitações deste trabalho, estão a utili- 
zação apenas dos resumos dos trabalhos e seus títulos e o fator de a abordagem metodológica não dar conta da totalidade das temáticas, mas apenas daquelas principalmente utilizadas.

\section{Referências}

ASSOCIAÇÃO NACIONAL DOS PROGRAMAS DE PÓS GRADUAÇÃO EM COMUNICAÇÃO. Comunicação e Cibercultura. [S.I.], 2013a. Disponível em:

<http://compos.org.br/ler_gts.php?idGt=Mg==>. Acesso em: 16 set. 2015.

ASSOCIAÇÃO NACIONAL DOS PROGRAMAS DE PÓS GRADUAÇÃO EM COMUNICAÇÃO. Biblioteca. [S.l.], 2013b. Disponível em: <http://compos.org.br/biblioteca.php>. Acesso em: 16 set. 2015.

BARDIN, L. Análise de conteúdo. São Paulo: Edições 70, 2011.

BASTOS, M. Outcompeting Traditional Peers? Scholarly Social Networks and Academic Output. In: HAWAII INTERNATIONAL CONFERENCE ON SYSTEM SCIENCES, 48., 2015, Kauai. Anais... Kauai: IEEE, 2015. p. 2043- 2052.

BRZEZINSKI, I.; GARRIDO, E. Análise dos trabalhos do GT Formação de Professores: o que revelam as pesquisas do período 1992-1998. Revista Brasileira de Educação, Rio de Janeiro, n. 18, p. 82-100, set./dez. 2001. Disponível em: <http://www.scielo.br/pdf/rbedu/n18/n18a08>. Acesso em: 16 set. 2015.

CARRIGNTON, P. J.; SCOTT, J.; WASSERMAN, S. Models and methods in social network analysis. Cambridge: Cambridge University, 2005.

DEGENNE, A.; FORSÉ, M. Introducing social networks. London: Sage, 1999.

GEPHI. [S.l.], c2015. Disponível em: <http://gephi.github.io/>. Acesso em: 16 set. 2015.

MENA-CHALCO, J. P., DIGIAMPIETRI, L. A., CESAR JUNIOR, R. M. Caracterizando as redes de coautoria de currículos Lattes. [S.l.], 2012. Disponível em:

$<$ http://professor.ufabc.edu.br/ jesus.mena/publications/pdf/menachalco2012coautorialattes.pdf>. Acesso em: 16 set. 2015.

NODEXL. [S.l.], c2015. Disponível em: <http://nodexl.codeplex.com/>. Acesso em: 16 set. 2015.

OSGOOD, C. The representational model and relevant research methods. In: SOLA POOL, I. de (Ed.). Trends in content analysis. Urbana: University of Illinois, 1959. p. 33-88.

PRIMO, A. et al. Análise de citações dos trabalhos da Compós 2008. E-compos, Brasília, v. 11, n. 3, set./dez. 2008. Disponível em: <http://compos.org.br/seer/index.php/ecompos/article/view/328/311>. Acesso em: 16 set. 2015. 
PRIMO, A. [Reproposição do GT Comunicação e Cibercultura. Porto Alegre, 2011]. Disponível em: <http://compos.com.pucrio.br/media/GT_comunicacao_e_cibercultura.pdf>. Acesso em: 16 set. 2015.

RECUERO, R.; BASTOS, M.; ZAGO, G. Análise de redes para mídia social. Porto Alegre: Sulina, 2015.

TREIN, E.; CIAVATTA, M. O percurso teórico e empírico do GT Trabalho e Educação: uma análise para debate. Revista Brasileira de Educação, Rio de Janeiro, n. 24, p. 141-164, set./dez. 2003. Disponível em: <http://www.scielo.br/pdf/rbedu/n24/n24a11>. Acesso em: 16 set. 2015.

WASSERMAN, S.; FAUST, K. Social network analysis. Cambridge: Cambridge University, 1994.

ZAGO, G.; BASTOS, M.; RECUERO, R. A endogamia da comunicação: redes de colaboração na CSAI. In: ENCONTRO ANUAL DA ASSOCIAÇÃ̃O NACIONAL DOS PROGRAMAS DE PÓSGRADUAÇ̃̃o EM COMUNICAÇÃO, 24., 2015, Brasília. Anais... Brasília: Compós, 2015. p. 123.

\title{
The Cyberculture Workgroup of Compós: an analysis on theme and coauthorship
}

\begin{abstract}
This study explores the works presented in the Cyberculture Workgroup of Compós by studying their patterns of theme and coauthorship. The objective was to discover which themes were more frequently addressed and how the members of the group came together in coauthored works through the years. We seek, through a methodology that combines content analysis and network analysis, to verify and measure the themes and collaborations in the workgroup, as well as offer insights on the group's scientific production and on its role as an inciter of coauthorship and collaboration among its researchers. As our main findings, we can point out two major emerging themes (digital culture and social networks on the Internet) and the low but growing presence of coauthorships in the group.
\end{abstract}

\section{Keywords}

Theme analysis. Coautorship analysis. Cyberculture. 